\title{
Streptococcus pneumoniae as an Unusual Aetiology of Meningitis Sepsis in a 72 Hours Newborn: A Case Report
}

\author{
Mirri G ${ }^{1,2}$, Borrominia $A^{3 *}$, Martinelli ${ }^{3}$, Maggiore $F^{3}$, Casero $D^{2}$, Veronelli E ${ }^{2}$ and Agosti $M^{4}$ \\ ${ }^{1}$ ASST Valle Olona, Department of Pediatric and Neonatology, S. Antonio Abate Hospital-Gallarate, C. Ondoli Hospital-Angera, Italy \\ ${ }^{2}$ ASST Valle Olona, Department of Pediatric and Neonatology, Saronno General Hospital, Italy \\ ${ }^{3}$ Department of Internal Medicine and Medical Therapy, University of Pavia, Medicine and Surgery School, Italy \\ ${ }^{4}$ ASST Dei Sett Laghi, Neonatology Unit, Neonatal Intensive Care Unit Filippo Del Ponte Hospital, Pediatric Unit of Verbano, Italy
}

*Corresponding author: Andrea Borromini, Department of Internal Medicine and Medical Therapy, University of Pavia, Medicine and Surgery School, Italy, Tel: +39348 887824; E-mail: andrea.borromini01@gmail.com

Received date: February 02, 2019; Accepted date: February 19, 2019; Published date: February 22, 2019

Citation: Mirri G, Borrominia A, Martinell N, Maggiore F, Casero D, et al. (2019) Streptococcus pneumoniae as an Unusual Aetiolog of Meningiti Sepsis In A 72 Hours Newborn: A Case Report. Arch Med Vol.11 No.1:2

Copyright: (2019 Mirri G, et al. This is an open-access articl distributed under the terms of the Creativ Commons Attributi License, which permits unrestricted use, distribution and reproductio in any medium, provided the original author and source are credited.

\section{Abstract}

We report a case of pneumococcal neonatal meningiti in an Italian girl, occurred 3 days afte birth. CSF microscopic examinatio revealed the presence of Gram Positiv diplococci, identifi as S. pneumoniae afte detectio of pneumococcal capsular antigen Tests for Group B Streptococcus on mother and child were both negative The case was peculiar because in industrialized countries the most common agents responsible of neonatal meningiti are GBS, E. coli and Listeria monocytogenes, where pneumococcal meningiti in the neonatal period is quite uncommon: It is then necessary to consider that, in any case of early onset neonatal meningitis $S$. pneumoniae is a possible yet uncommon causativ agent, and that the microbiological profil of early onset neonatal meningiti in industrialized countries might change substantiall because of migratory streams and the subsequent diffusio of emerging microorganisms, which are unusual at the present time

\section{Keywords: Pneumoniae; E. coli; Meningitis Neonatal}

\section{Introduction}

We talk of neonatal meningiti when a microorganism is isolated in CSF during the firs month of extra uterine life. Clinically, this infectio is usually presents as a septi conditio associated to neurological signs such as irritability, seizures, muscle hyper tony, vomiting sharp cry, hyperpyrexia and pulsing anterior fontanelle. In pediatric populatio mortality rates vary from $20 \%$ to $40 \%$ with a $20 \%$ risk of CNS sequelae and permanent acousti dysfunctions particularl related to pneumococcal infectio [1]. The most frequent cause of neonatal meningiti is Group B Streptococcus (GBS), with vertica transmission. Pneumococcal infectio can be transmitte through contact with infected subjects or asymptomati carriers, while vertica transmission is a rare yet possible occurrence. The incubatio period may vary from 1 to 3 days. This case report is aimed to be an additio to the existin literature regarding cases of neonatal meningitis considered that in industrialized countries this infectio stil is, along with sepsis and pneumonia, the firs cause of death of the newborn in the firs 60 days of life, advancements in antibio therapy notwithstanding [2].

\section{Case Description}

The patien was given birth at 41 weeks and 2 days, afte labor was induced because of oligohydramnios; no other complication occurred during pregnancy and maternal serologic tests for Group B Streptococcus were negative At birth, the patien showed good adaptatio to extra uterine life (APGAR 10/10 at 1 and 5 minutes) and both anthropometric measurements and weight were within normal range. At day 3 afte birth, because of the onset of hyperpyrexia, trunk and limb rigidity and sunset eyes, blood tests were carried out, showing an increase in inflammator markers (PCR $10.9 \mathrm{mg} /$ $\mathrm{dl}$ ). At the same tim blood culture was found positiv for $S$. Aureus and S. Warneri, while urine culture was found positiv for Serrati Marcescens (>100.000 CFU/ml), for this reason empirical antibio therapy with intravenous Ampicilline and Metilmicin was initiated The patien was then transferred to neonatal ICU afte her clinical conditio worsened, with hypo reactivity axial hypo tony, limb hyper tony, absence of the refle of Moro, shrill cry, pallor and mild jaundice. A lumbar puncture was then performed because of the suspicion of CNS involvement: the turbid appearance of the CSF sample suggested continuin antibio therapy with Ampicilline, Sulbactam and Amikacine. CSF laboratory examinatio showed an elevated protein concentratio and WBC count, while microscopic examinatio revealed the presence of Gram 
positiv diplococci, further confirme when PCR detected the presence of $S$. pneumoniae capsular antigen no viral DNA was found. Blood tests showed an elevated WBC count (13210 $\mathrm{mm} 3)$ and a further raise in PCR $(177 \mathrm{mg} / \mathrm{dl})$; the subsequent blood culture was positiv for Meticillin resistant strains of $S$. Aureus and S. Epidermidis, which forced to replace Amikacine with Vancomicine. Such therapy was continue unti day 14

In order to further investigat the patient' neurological condition diagnosti imaging procedures were carried out: serial brain echography evidenced a marked oedema without signs of activ hemorrhagic foci. Hemi cranial electroencephalography detected nonspecificall anomalies in the front cerebral regions and subsequent MRI showed no signs of hemorrhagic, ischemic or expansive lesions. Serum levels of immunoglobulins and complement factors were then investigate because an immunodeficienc conditio was suspected, but no abnormalitie were found. Other blood tests were carried out during the following period of hospitalization showing a progressive decrease in both inflammator and infectio markers, unti their complete normalizatio at day 26, afte which the patien was discharged with a fina diagnosis of $S$. pneumoniae meningitis At discharge, physical examinatio showed no abnormalities the patien fed well with both maternal and artifici milk, with a weight gain of 850 g. Neurologic and auditory follow up exams were then programmed.

\section{Discussion}

The causativ agents of neonatal bacterial meningiti are differen geographically. In most developed countries the main causativ agents for neonatal bacterial meningiti isolated from cerebrospinal flui (CSF) are Group B Streptococcus (GBS), E. coli, Listeria monocytogenes and at least $S$. pneumonia. The Reasons for this may include geneti difference in immune response and possibly geographic difference in laboratory techniques for pathogen isolatio and reportin and they are also influence by maternal and infant risk factors, preventio and treatment strategies of the country [3]. Pneumococcal meningiti in the neonatal period is uncommon (only 28 cases reported in literature before 1945), however it's related to high mortality and morbidity rates, in particula neurological sequelae are a frequent occurrence. Neonatal and maternal risk factors for developing neonatal meningiti include low birth weight, prematurity, premature ruptures of membranes, maternal chorioamnioniti and low socioeconomic status. The newborn is particularl susceptibl to infectio as the immature immune system is deficien in humoral and cellular immune responses: for this reason the patient' immune state has been assessed, but test finding were normal. On the other hand, the importance of maternal infectio was already highlighted by Berman and Banner in 1922, when they observed in their study that, in more than half of mothers with affecte newborns, the same microorganism was isolated. The evidence that obstetrical complication increase the risk of infection and that infectio occurs within six days afte birth, suggests that it is transmitte during childbirth, through placenta or birth canal [4]. However,
S. pneumoniae is not usually part of the vaginal flora and it is present only in $0.03 \%$ to $0.75 \%$ of pregnant women [5]. Meningitis as in the case here discussed, is accompanied by sepsis in $25 \%$ of cases, not necessarily caused by the same microorganism. This result in increased morbidity and mortality rates [6]. These elements lead to the following observations if meningiti is suspected, it is necessary to initiat an aggressive empirical antibio treatment, which must extend to all the pathogen agents potentiall involved: the combinatio of ampicillin with an aminoglycoside, or a third generatio cephalosporin, is effectiv However, it is necessary to consider that also $S$. pneumoniae is a possible etiologica agent, which responds well to the administratio of Vancomicine, and that such treatment must be initiate when microscopic confirmati is available: the findin of Gram positiv diplococci in the blood smear is sufficien as suggested by Yagmur Bas [6]. Moreover, considered that $S$. pneumoniae is an uncommon agent in neonatal meningitis it is advisable to investigat the state of cellular immune response of the affecte newborn, in order to rule out any immunodeficienc condition

\section{Conclusion}

A large scale world health organizatio (WHO) study conducted in various countries of meningiti belt has documented that $S$. pneumoniae being the most common organism. This lead us to the hypothesis that, in the next years, the microbiological profil of early-onset neonatal meningiti in industrialized countries will change substantiall because of migratory streams and the subsequent diffusio of emerging microorganisms, which are unusual at the present time Perhaps, new infectiv screening panels will be necessary during pregnancy, in order to carry out a highly effecti antibio prophylaxis, rationall based on laboratory findings In Spain, there are 16 published cases of neonatal pneumococcal disease: 14 with early-onset and 2 with lateonset. 6 The administratio of heptavalent pneumococcal vaccines over recent years, and most recently the 10- and 13valent types (including the $7 \mathrm{~F}, 3$, and $6 \mathrm{~A}$ serotypes, which are an important cause of invasive pneumococcal disease worldwide), has reduced the transmission of diseases due to pneumococcus in the general populatio (from 50-100 to 9 cases for every 100000 people) and, consequently, the incidence of neonatal invasive pneumococcal disease has decreased. Vaccinatio during the third trimester of gestatio could be a measure to follow in the future, although there are no conclusive studies that currently confir this. Cases such as the one here described demonstrate how molecular research, through the actuatio of new diagnosti methods, is nowadays vital to reach an etiologica diagnosis, in particula for those infection requiring prompt treatment in order to decrease morbidity and mortality rates. This case report allows highlightin that in medicine, paradigms are subject to continuou evolutio and changes, which force clinicians to adopt new diagnosti and therapeuti strategies, especially in infectiou field where statisti show a constant evolutio of etiologica profile of the main diseases which need, in the 
neonatal period, prompt treatment with the appropriate instruments.

\section{References}

1. Jill AH (2003) Streptococcus pneumoniae, infectiou in the neonate. Pediatrics V. 112: 1095-1102.

2. Shaye ZA, Alaee E, Shaye MA, Bakhtiar M (2015) Neonatal meningiti caused by Streptococcus pneumonia in Iran. IJN 6: 35-38.

3. Reta MA, Zeleke TA (2016) Neonatal bacterial meningiti in Tikur Anbessa Specialized Hospital, Ethiopia: A 10-year retrospectiv review. SpringerPlus 5: 1971.
4. Tempest B (1974) Pneumococcal meningiti in mother and neonate. Pediatrics 53: 759-760.

5. Hermoso TC, Carrasco ZM, Ferrer MT (2012) Streptococcus pneumoniae: An unusual pathogen in neonatal sepsis of vertica transmission. Arch Bronconeumol 48: 425-426.

6. Bas AY, Demirel N, Aydin M, Zenciroglu A, Tonbul A, et al. (2011) Pneumococcal meningiti in the newborn period in a prevaccinatio era: A 10-year experience at a Tertiar Intensive Care Unit. Turk J Pediatr 53: 142-148. 